\title{
Preparation of Activated Carbons based Balanites Aegyptiaca Shells by Chemical Activation: Optimization Conditions Using the Methodology of Experimental Design
}

\author{
René B. N. Lekene, Naphtali O. Ankoro, Ndi J. Nsami, Daouda Kouotou, Abdoul N. Rahman, and
}

Ketcha J. Mbadacam

\section{ABSTRACT}

The optimization conditions of preparation of activated carbons based Balanites aegytiaca shells by chemical activation was investigated. The effects of three parameters of preparation namely, the activation temperature $(600$ $\left.800{ }^{\circ} \mathrm{C}\right)$, impregnation ratio $(1: 4-3: 8)$ and residence time $(60-120 \mathrm{~min})$ were thoroughly studied on the activated carbon yield $\left(Y l d, Y_{l}\right)$, iodine number $\left(I O N, Y_{2}\right)$ and methylene blue number $\left(M B N, Y_{3}\right)$ using the Methodology of Experimental Design (MED). The analysis of variance (ANOVA) under the experimental domain revealed that, the activation temperature of $800{ }^{\circ} \mathrm{C}$, residence time of $02 \mathrm{hrs}$ and impregnation ratio of $1: 2$ were the optimum conditions of preparation leading to activated carbon yield of $23.0 \%$, iodine number of $889.0 \mathrm{mg} / \mathrm{g}$ and methylene blue number of $9.7 \mathrm{mg} / \mathrm{g}$. The polynomial equation showed that the three parameters were both synergetic and antagonistic on the responses retained. The higher values of iodine numbers obtained alongside the experimental matrix is an indication that the activated carbons so prepared were mainly microporous.

Keywords: Activated carbon, Adsorption, ANOVA, Balanites aegyptiaca, Optimization.

\section{INTRODUCTION}

The management of huge amount of wastes is still a matter of concern to population confronted to these bigger discharges. This consequently caused environmental problem due to their accumulation which of course creates damages such as air, soils, and water pollution [1], [2]. The problem is more visible for the bigger producers of wastes like
Published Online: December 18, 2020

ISSN: $2684-4478$

DOI :10.24018/ejchem.2020.1.6.33

R. B. N. Lekene

Physical and Theoretical Chemistry

Laboratory, Department of Inorganic

Chemistry, Faculty of Science, University

of Yaoundé I, Cameroon.

(e-mail: lekeneblaise@ ${ }^{\circledR}$ ahoo.fr)

N. O. Ankoro

Physical and Theoretical Chemistry

Laboratory, Department of Inorganic

Chemistry, Faculty of Science, University

of Yaoundé I, Cameroon.

(e-mail: a.naphtali@yahoo.com)

N. J. Nsami

Physical and Theoretical Chemistry Laboratory, Department of Inorganic

Chemistry, Faculty of Science, University of Yaoundé I, Cameroon.

(e-mail: bigpielo2002@yahoo.com)

D. Kouotou*

Physical and Theoretical Chemistry Laboratory, Department of Inorganic Chemistry, Faculty of Science, University of Yaoundé I, Cameroon.

(e-mail: kouotoudaouda@ gmail.com)

A. N. Rahman

Department of Chemistry, Higher

Teacher's Training College of Bertoua,

University of Ngaoundéré, Cameroon.

(e-mail: rahmino@gmail.com)

K. J. Mbadacam

Physical and Theoretical Chemistry Laboratory, Department of Inorganic Chemistry, Faculty of Science, University of Yaoundé I, Cameroon.

(e-mail: jketcha@ ${ }^{@}$ ahoo.com)

*Corresponding Author agricultural industries of products transformation. For this reason, more interest is given to the valorization of these wastes which are produced and discharge in the environment [3]. It is interesting to know that the valorization does not consider these agricultural by-products like wastes properly which must be throw away, but consider them as a precursor to be exploited and gives an added value. The access to combustible for cooking purpose is still another problem 
faced by many countries, these populations used agricultural residues like Balanites aegyptiaca shells as a source of energy, which of course favorite the production of green gas which are not good for the ozone layer. Therefore, it is advised to put in place ecological and economical techniques which are capable to valorize these wastes as adsorbents materials with high added value [3], [4]. The necessity to find sustainable adsorbents with zero damage to the environment are the economic and environmental challenges face by researchers nowadays. Thus, the elaboration of activated carbons based agricultural residues seems to be a good and right solution, since the activated carbons demand is still increasing around the world [5]. The conversion of agricultural residues into activated carbons is a way of valorization which has been proof and recognized industrially because applied to many residues such as mangoes seeds [6], rice husk, nuts shells, coconut shells [7], oil palm shells [3, 4, 8]; palm kernel shells [9], cola nut shells [10], [11]. The Balanites aegyptiaca residues are agricultural by-products that are used in reason of their lignocellulosic nature. Balanites aegyptiaca is a specie particularly abundant and available in sahelian regions and which have important utilization. Their fruits are used as foods for human beings and animals. All the parts of the Balanites aegyptiaca tree are used in traditional medicine for the treatment of many diseases like psychoses, epilepsy, rheumatisms, coughs, and rate [12]. This plant has been more studied in the domain of foods for human beings [13], animals [14] and also in the medical domain [15]. As, Balanites aegyptiaca shells are available and abundant and discharge in the environment, it was interesting, to find whether they can be converted into activated carbons for more used. Primarily, it is necessary for the production of activated carbons of good quality, to have deep knowledge on the precursor which is the starting material, particularly their physicochemical properties [3], [5]. The present work deals with the valorization of endocarp of the Balanites aegyptiaca fruits into activated carbons by chemical activation. As the literature well described, there are many methods of production of activated carbons such as physical activation, chemical activation even physicochemical activation [3], [5], [9], [10]. But amongst the aforementioned method, the chemical activation has the merit to create important porosity and avoid consumption of more energy compared to the other two methods [2]-[4]. The Balanites aegyptiaca is a ligneous plant which grows under various ecological conditions (100 $\mathrm{mm}$ to $1000 \mathrm{~mm}$ of rains per year), and it is abundant in arid and semi-arid regions in tropical Africa [16], this availability is one of the criteria of choice of activated carbons precursors [3]-[5]. Even though the Balanites aegyptiaca is consider as a versatile plant because of its various utilizations as showed above, and considering the fact that, researches are growing to find out good precursors for production of activated carbons, there are not much studies dealing with the utilization of Balanites aegyptiaca for the production of activated carbons as far as our knowledge is concerned [...]. Thus, the aim of this work is to use initial analysis like iodine and methylene blue numbers to show that, the Balanites aegyptiaca can be used for the production of activated carbons. To achieve this goal, the methodology of experimental design which was used in literature for similar purpose [3]-[6,] [17], [18] was deeply used in this work to investigate and find out the optimum conditions of preparation of outstanding activated carbons based Balanites aegyptiaca shells.

\section{MATERIALS AND METHODS}

\section{A. Sample Collection}

The Balanites aegyptiaca residues were sampled by an association called Tiipaalga in Burkina Faso. This association collected the Balanites aegyptiaca fruits in order to use the seeds for the oil production. The Balanites aegyptiaca shells were obtained by sampling the fruits directly on the tree and also by collecting the shells that animals leave after eating and digesting the seeds. The Balanites aegyptiaca shells were washed, dried, grinded and sieved into particles sizes ranged between $1.00-3.15 \mathrm{~mm}$.

\section{B. Experimental Methods}

$10.0 \mathrm{~g}$ of $\mathrm{KOH}$ were dissolved in $250 \mathrm{~mL}$ conical flasks with distilled water. In another $500 \mathrm{~mL}$ conical flask, the prepared solution of $\mathrm{KOH}$ and a known mass of Balanites aegyptiaca shells at the desired impregnation ratio (v:w) were mixed. The mixture was shaken during 2 hours and at the temperature of $25^{\circ} \mathrm{C}$. Once the time of impregnation was reached, the mixture was filtrated and dried in an oven overnight. After, the impregnation step, the activation process was done in a Carbolite furnace at the pyrolysis temperature varying between $600-800{ }^{\circ} \mathrm{C}$ under nitrogen gas flow for a residence time ranging from 60 to $120 \mathrm{~min}$. When the activation process was achieved, the activated carbons obtained were washed with a $0.1 \mathrm{~N}$ hydrochloric acid solution, followed with distilled water until the $\mathrm{pH}$ range of 6-7. The obtained activated carbons based Balanites aegytiaca shells were dried at $105{ }^{\circ} \mathrm{C}$ for 24 hours. Finally, after drying, the samples were grinded and sieved to the particles size less than $0.212 \mathrm{~mm}$.

TABLE 1: The FACTORS THAT AFFECT THE PREPARATION OF ACTIVATED CARBON AND THEIR DIFFERENT LEVELS

\begin{tabular}{|c|c|c|c|}
\hline Factor & \multicolumn{2}{|c|}{ Low level value } & $\begin{array}{l}\text { High level } \\
\text { value }\end{array}$ \\
\hline $\begin{array}{c}\mathrm{X}_{1}: \text { Activation } \\
\text { temperature }\left({ }^{\circ} \mathrm{C}\right)\end{array}$ & 600 & 700 & 800 \\
\hline $\begin{array}{c}\mathrm{X}_{2}: \text { Residence time } \\
(\mathrm{min})\end{array}$ & 60 & 90 & 120 \\
\hline $\begin{array}{c}\mathrm{X}_{3}: \text { Impregnation } \\
\text { ratio }\end{array}$ & $1 / 4$ & $3 / 8$ & $1 / 2$ \\
\hline
\end{tabular}

\section{Methodology of Experimental Design}

The Methodology of Experimental Design (MED) is a statistical technique for modeling and analysis of problems in which a response of interest is influenced by several factors [3], [4], [18]. The MED is utilized to optimize the effective parameters with a minimum number of experiments, as well as to analyze the interactions between the parameters [3], [4]. The three factors investigated in the present work (Table1) were coded as the activation temperature $\left(X_{1}\right)$, impregnation ratio $\left(X_{2}\right)$ and the residence time $\left(X_{3}\right)$. The three responses analyzed were the activated carbons yield, Yld (\%); iodine 
number, ION (mg/g); and methylene blue number, MBN $(\mathrm{mg} / \mathrm{g})$. Each response was used to develop a model which correlates the responses to the three coded factors using a polynomial equation given by the following equation:

$$
\begin{aligned}
& Y=a_{0}+a_{1} X_{1}+a_{2} X_{2}+a_{3} X_{3}+a_{12} X_{1} X_{2}+a_{13} X_{1} X_{3}+ \\
& a_{23} X_{2} X_{3}
\end{aligned}
$$

where, $Y$ is the predicted response, $a_{0}$ is a constant coefficient, $a_{i}$ is a linear coefficient; $a_{i j}$ is an interaction coefficient; $X_{l}$, $X_{2}$ and $X_{3}$, are the coded values of the factors. The Full Factorial Design (FFD) using three factors was used to generate an experimental matrix of twelve experiments including four experiments at the center of the studied domain. The experiments at the center points were used to determine the experimental error and to verify the reproducibility of experimental data. This FFD has been chosen, because it helps to observe the influence of different factors on the responses studied. The experimental data were analyzed using a statistical software design expert named NEMROD, for regression analysis to fit the equations developed and also to evaluate the statistical significance of the equations obtained.

\section{Activated Carbons Characterizations}

Prior characterizations of activated carbons consisted of the determination of the yield, iodine, and methylene blue numbers. Of course, the sample of activated carbon have been grinded in the porcelain mortar and sieved at the particles sieved of $212 \mu \mathrm{m}$ as described above.

\section{The activated carbons yield}

The determination of the activated carbons yield helps to estimate the quantities of activated carbons that can be obtained from an initial mass of precursor. Practically, it is to determine the ratio of the weight percent of carbon obtained after pyrolysis of the initial mass of precursor used. It is calculated from the following formula:

$$
R=\frac{\mathrm{m}}{\mathrm{m}_{o}} \times 100
$$

where,

$m$ and $m_{0}$ are the mass of carbon obtained after pyrolysis and the mass of initial biomass used respectively $(\mathrm{g})$.

\section{Iodine number}

Iodine number is a test which gives an indication on the microporosity of activated carbons, in another words, the measurements of the capacity to adsorb molecules of small sizes (less than $10 \AA$ ) [19]. Iodine was considered as probe molecule for assessing the adsorption capacity of adsorbent for solutes of molecular sizes $<10 \AA$. The iodine number is defined as the milligrams of iodine adsorbed by $1 \mathrm{~g}$ of carbon. The iodine adsorption was determined using the sodium thiosulfate volumetric method (ASTM D4607-94, 2006) [20]. The iodine number was estimated by mixing the activated carbon with $0.02 \mathrm{~N}$ iodine solution shaken occasionally and then by titration of the solution against $\mathrm{Na}_{2} \mathrm{~S}_{2} \mathrm{O}_{3}$ as well described in our earlier work [3]. The iodine number, ION $(\mathrm{mg} / \mathrm{g})$ is calculated from the following formula:

$$
\mathrm{ION}=\frac{25.4 \times(20-\mathrm{Vthio})}{\mathrm{m}_{A C}}
$$

where,

$V_{\text {thio }}$ is the volume of $\mathrm{Na}_{2} \mathrm{~S}_{2} \mathrm{O}_{3}$ solution $(\mathrm{mL})$.

$m_{C A}$ is the mass activated carbon ( $\mathrm{mg}$ ).

\section{Methylene blue number}

This index gives an indication on the capacity of activated carbon to adsorb molecules medium and large sizes (between 15-28 $\AA$ ) [19]. Methylene blue (MB) was considered as probe molecule for assessing the adsorption capacity of adsorbent for solutes of molecular sizes $>15 \mathrm{~A}^{\circ}$. The methylene blue number is the milligrams of methylene blue adsorbed by $1 \mathrm{~g}$ of carbon [21]. The concentration of methylene blue was measured by using a beam UV-visible spectrophotometer Miltonroy Company Spectronic 20D at the maximum absorbance wavelength of $664 \mathrm{~nm}$. The methylene blue number $M B N(\mathrm{mg} / \mathrm{g})$ was calculated using the following formulae:

$$
M B N=\frac{\left(\mathrm{C}_{o}-\mathrm{C}_{f}\right)}{\mathrm{m}_{A C}} \times V
$$

where,

$\mathrm{V}$ is the volume of methylene blue solution de $(\mathrm{mL})$.

$C o$ and $C_{f}$ are initial and final concentration of the $\mathrm{MB}$ solution $(\mathrm{mg} / \mathrm{L})$ respectively.

$m_{C A}$ is the mass activated carbon $(\mathrm{mg})$ in contact with methylene blue solution.

\section{RESULTS AND DISCUSSION}

\section{A. Immediate Analysis of Balanites aegyptiaca Shells}

The aim of this immediate analysis was to determine the contents of main constituents of Balanites aegyptiaca shells used. The results of different analysis are compiled in the Table 2. The results of immediate analysis revealed that Balanites aegyptiaca shells have a low moisture and ash contents but, have high content in fixed carbon and volatiles matters. Additionally, the Balanites aegyptiaca shells revealed their character of lignocellulosic material according to the lignin, cellulose and hemicellulose contents. Thus, their thermochemistry valorization in activated carbons is interesting compared to others works in the literature [3], [4], [7], [11], [18].

TABLE 2: IMMEDIATE ANALYSIS OF MAIN CONSTITUENTS OF BALANITES

\begin{tabular}{cc}
\multicolumn{2}{c}{ AEGYPTIACA SHELLS } \\
\hline Components & Weight percent $(\%)$ \\
\hline Moisture & 4.86 \\
Volatiles matters & 80.19 \\
Ash & 4.21 \\
fixed carbon & 15.60 \\
Extract & 9.66 \\
Hemicellulose & 33.88 \\
Lignin & 15.17 \\
Cellulose & 41.29 \\
\hline
\end{tabular}

\section{B. Analysis of the Experimental Design}

The combination of different factors is provided by the experimental design, such that the observation of influence (inner and interaction effects) of these different factors on the 
three responses studied and the determination of optimum condition of preparation of activated carbons be possible. The experiments done help to determine the responses. The results obtained after execution of the matrix are interpreted using the ANOVA. The model predicted, is analyzed by the values of correlation coefficients. The indicators of validity of the model are $R^{2}$ and $R^{2}$-adjusted which values must be closed to unity to confirm the fitting of the model postulated. For the polynomial equation given the different responses in function of the factors investigated, a positive sign in front of the coefficients indicates synergistic effects, whereas negative sign indicates antagonistic effects.

TABLE 3: EXPERIMENTAL MATRIX AND THE DIFFERENT RESPONSES OBTAINED

\begin{tabular}{ccccccc}
\hline $\mathrm{N}^{\circ}$ & $\begin{array}{c}\text { Activation } \\
\text { temperature } \\
\left(X_{I}\right)\end{array}$ & $\begin{array}{c}\text { Residence } \\
\text { time } \\
\left(X_{2}\right)\end{array}$ & $\begin{array}{c}\text { Impregnat } \\
\text { ion ratio } \\
\left(X_{2}\right)\end{array}$ & $\begin{array}{c}Y_{l} \\
(\%)\end{array}$ & $\begin{array}{c}Y_{2} \\
(\mathrm{mg} / \mathrm{g})\end{array}$ & $\begin{array}{c}Y_{3} \\
(\mathrm{mg} / \mathrm{g})\end{array}$ \\
\hline 1 & 600 & 120 & $1: 2$ & 26.55 & 165.10 & 3.03 \\
2 & 800 & 120 & $1: 4$ & 22.51 & 774.70 & 9.81 \\
3 & 800 & 60 & $1: 2$ & 24.93 & 476.25 & 4.95 \\
4 & 600 & 60 & $1: 2$ & 27.64 & 209.55 & 2.84 \\
5 & 800 & 60 & $1: 4$ & 23.47 & 527.05 & 3.49 \\
6 & 600 & 120 & $1: 4$ & 25.12 & 215.90 & 4.18 \\
7 & 600 & 60 & $1: 4$ & 26.12 & 177.80 & 3.63 \\
8 & 800 & 120 & $1: 2$ & 23.00 & 889.00 & 9.70 \\
9 & 700 & 90 & $3: 8$ & 25.35 & 374.65 & 4.01 \\
10 & 700 & 90 & $3: 8$ & 25.31 & 488.95 & 3.74 \\
11 & 700 & 90 & $3: 8$ & 24.60 & 361.95 & 5.55 \\
12 & 700 & 90 & $3: 8$ & 24.18 & 374.65 & 6.55 \\
\hline
\end{tabular}

$Y_{l}=$ response of activated carbon yield.

$Y_{2}=$ response of iodine number.

$Y_{3}=$ response of methylene blue number.

The analysis of the Table 3 above, showed that the activated carbons yield varied from 22.51 to $27.64 \%$. The iodine numbers varied from 165.10 to $889.00 \mathrm{mg} / \mathrm{g}$ and the methylene blue from 2.84 to $9,81 \mathrm{mg} / \mathrm{g}$. It can be notice that the higher values of activated carbons yield are obtained for the activation temperature of less than $600{ }^{\circ} \mathrm{C}$ and residence time less than $60 \mathrm{~min}$, whereas, the lower values of activated carbon yield are obtained at $800{ }^{\circ} \mathrm{C}$ and 120 min for activation temperature and residence time respectively. This can be explained by the fact that, there are rupture of chemical bonds in the biomass network with the increase of activation temperature, which conducted to the release of volatiles matters and thus reducing progressively the mass of the samples. The similar trends have been observed in our earlier works [3], [4]. The longer the residence time the higher the time of reaction. The higher values of iodine and methylene blue numbers are obtained for higher activation temperatures and residence time $\left(800^{\circ} \mathrm{C}\right.$ and $\left.120 \mathrm{~min}\right)$ whereas, the lower values iodine and methylene blues are obtained at activation temperatures and time of residence which are lower $\left(600{ }^{\circ} \mathrm{C}\right.$ and $60 \mathrm{~min})$. In fact, the increase of activation temperature conducts to the opening and the widening of pores, which consequently increase the adsorption iodine and methylene blue molecules. The higher values of iodine number (between 165.10 and $889.00 \mathrm{mg} / \mathrm{g}$ ) compared to the lower values of methylene blue (between 2.84 and $9.81 \mathrm{mg} / \mathrm{g}$ ) indicated clearly that the activated carbons have the capacity to adsorb molecules with the particle's sizes less than $2 \mathrm{~nm}$. Therefore, the porosity of activated carbons obtained are predominated by micropores and this assertion can be confirmed by rigorous equipment of surface analysis.

\section{Statistical Analysis}

The synthesis of ANOVA (Table 4) gives the probabilities of each factor and their coefficient of interaction when the two factors are taken together in function of the different responses. The Table 4 below showed that for the activated carbons yield $\left(Y_{1}\right)$, the factors having a probability less than 0.05 with a confidence interval of $95 \%$, were the activation temperature $\left(X_{1}\right)$, impregnation ratio $\left(X_{2}\right)$ and residence time $\left(X_{3}\right)$. For the iodine $\left(Y_{2}\right)$ and methylene blue $\left(Y_{3}\right)$ numbers, the factors having a probability less than 0.05 were the activation temperature $\left(X_{1}\right)$, the residence time $\left(X_{3}\right)$ and the interaction between these two factors $\left(X_{1} X_{3}\right)$. This means that the above factors cited were significantly different of zero at the confidence level of $95 \%$ and therefore, only these factors have significant effects on different responses where they are linked.

\begin{tabular}{cccc} 
TABLE 4: ANALYSIS OF VARIANCE OF RESPONSES OBTAINED \\
\hline & \multicolumn{3}{c}{ Probability } \\
\cline { 2 - 4 } & $Y_{1}$ & $Y_{2}$ & $Y_{3}$ \\
\hline$X_{1}$ : Activation temperature & 0.0003 & 0.0001 & 0.0050 \\
$X_{2}$ : Impregnation ratio & 0.0136 & 0.8164 & 0.8528 \\
$X_{3}$ : Residence time & 0.0126 & 0.0155 & 0.0109 \\
$X_{1} \cdot X_{2}$ & 0.573 & 0.0144 & 0.0183 \\
$X_{1} \cdot X_{3}$ & 0.4701 & 0.6685 & 0.3232 \\
$X_{2} \cdot X_{3}$ & 0.4512 & 0.6685 & 0.5462 \\
$R^{2}$ & 95.53 & 96.46 & 91.20 \\
$R^{2}$-ajusted & 0.17 & 92.21 & 80.63 \\
\hline
\end{tabular}

Additionally, the analysis of Table 5, also showed that for the three responses studied, $R^{2}$ and $R^{2}$-adjusted have the values greater than $80 \%$, exception done for the activated carbon yield where the $R^{2}$-adjusted was 0.17 . The different values of $R^{2}$ indicated that the adjusted model explained respectively $95.53 \%$ of the variability of activated carbons yield; $96.46 \%$ of variability of iodine numbers and $91.20 \%$ of variability of methylene blue numbers. This consideration conducted to the conclusion that the model predicted is validated.

\section{Mathematical Modeling of the Responses and Analysis of Effects of Different Factors}

The expressions of different responses are given in equations below:

$$
\begin{gathered}
Y_{1}=24.8973-1.43875 X_{1}-0.623625 X_{2}+ \\
0.611625 X_{3}-0.098575 X_{1} X_{2}-0.128125 X_{1} X_{3}- \\
0.134 X_{2} X_{3} \\
Y_{2}=419.629+237.331 X_{1}+81.7563 X_{2}+5.55625 X_{3}+ \\
83.3438 X_{1} X_{2}+10.3187 X_{1} X_{3}+10.3188 X_{2} X_{3} \\
Y_{3}=5.12208+1.78362 X_{1}+1.47538 X_{2}+ \\
0.073125 X_{3}+1.29113 X_{1} X_{2}+0.410125 X_{1} X_{3}+ \\
0.242125 X_{2} X_{3}
\end{gathered}
$$

When a positive sign is in front of a coefficient, this means that the factor has a synergetic effect on the response, consequently, its increase conducts to the increase of the 
response and inversely. Whereas a negative sign in front of the coefficient indicates an antagonistic effect, thus its increase causes the decrease of the response concerned and inversely. According to the polynomial equations above, for Yld $\left(Y_{l}\right)$ only the impregnation ratio has a synergetic effect. For ION $\left(Y_{2}\right)$, all the factors have synergetic effect, which of course shows that, all the factors favored the production of micropores on the adsorbent. For $M B N\left(Y_{3}\right)$, all the factors have synergetic effect exception for the impregnation ratio and the interaction coefficient of activation temperature and impregnation ration. This trend can be explained by the fact that, the impregnation with $\mathrm{KOH}$ generally promote the formation of micropores. But it can be noticed that the $M B N$ is two low with Balanites aegyptiaca activated with $\mathrm{KOH}$. This observation is similar to the one observed in our earlier work, where the oil palm shells was impregnated in one hand by $\mathrm{KOH}$ and $\mathrm{H}_{3} \mathrm{PO}_{4}$. It was clearly demonstrated that, oil palm shells activated with $\mathrm{KOH}$ was mostly adsorbed Iodine rather than methylene blue [3], [4]. The analysis of the Pareto diagrams for the activated carbons yield (Fig. 1a) revealed that, the activation temperature was the factor having the significant effect followed by the residence time and the impregnation ratio which have moderated. This significance of activation temperature on the activated carbon yield can be explained because, the increase in activation temperature would involve the release of volatiles matters as the result of intensifying dehydration and elimination reactions as well as increasing the $\mathrm{C}-\mathrm{KOH}$ reaction rate, thus the decrease in activated carbons yield [3], [22]-[24]. Additionally, when the activation temperature increased, the gasification reactions allowed the liberation of the entrances of the pores blocked by amorphous matters, thus Baçaoui et al. observed the same trends of decreasing in activated carbons yield in the work dealing with olive-wastes cake optimizations conditions of preparation [5]. It can be also observed that, increasing activation temperature and impregnation ratio conducted to increase the carbon burn off, this weight loss was attributed to huge elimination reactions [3], [24], which affected significantly Balanites aegyptiaca shells and then reduced the yield. The interactions effects $\left(X_{2} X_{3}, X_{1} X_{3}\right.$ and $\left.X_{1} X_{2}\right)$ have low values indicating that the factors put together do not have significant effects the activated carbon yield.

The Pareto diagrams for the iodine number (Fig. 1b) shows that the activation temperature have the most significant effect whereas the impregnation ratio and the interactions $\left(X_{2} X_{3}, X_{1} X_{3}\right)$ have not significant effects. But the interaction $\left(X_{1} X_{2}\right)$ has a moderate significant effect on iodine number. The Pareto diagrams for the methylene blue (Figure 1c) revealed that, the activation temperature, residence time and their interaction $\left(X_{1} X_{2}\right)$ have the most significant effect. On contrary, the impregnation ratio and the interactions $\left(X_{2} X_{3}\right.$ and $X_{1} X_{3}$ ) have the low effects thus they are not significant for the adsorption of methylene blue.
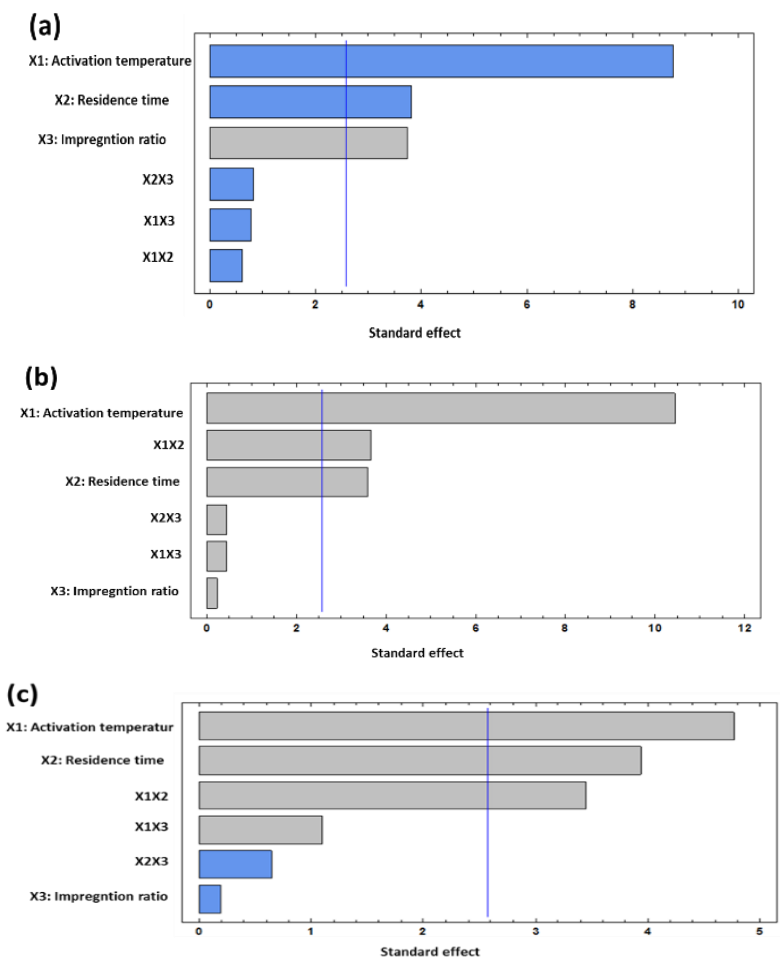

Fig. 1. Pareto graphics of (a) activated carbon yield, (b) iodine and (c) methylene blue number

\section{E. Responses Surfaces}

At each point of the experimental domain corresponds a response, thus for the set of points of the experimental domain investigated corresponds a set of responses called responses surface. Therefore, it is possible to predict the values that the different of responses will have inside the experimental domain studied. On the response's surfaces represented below, it can be noticed the evolution of different responses in function of the three factors. Fig. 2 shows the both synergetic effects of activation temperature and residence time on the iodine (Fig. 2a) and methylene number (Fig. 2b).
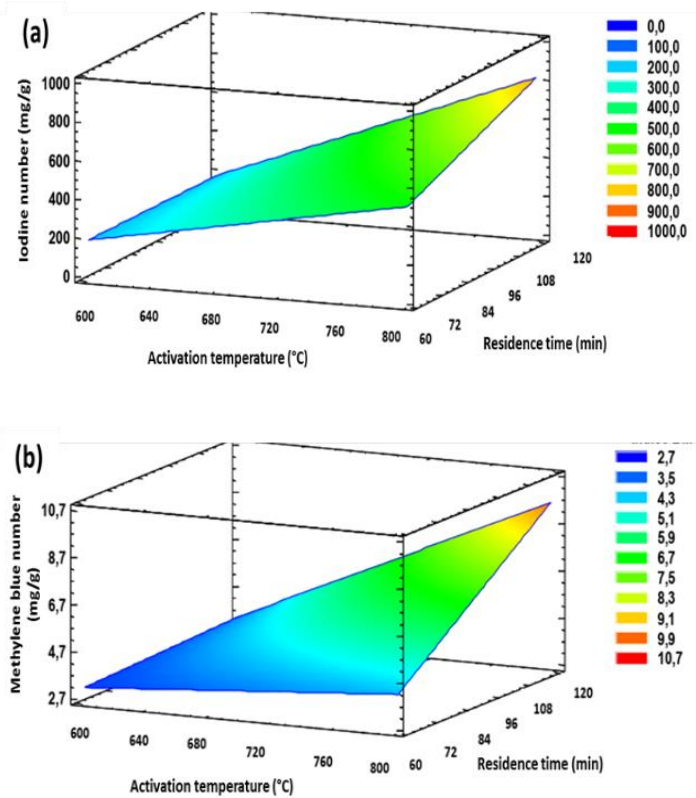

Fig. 2. Response surface of (a) iodine number and (b) methylene blue number in 3D. 


\section{F. Optimum Conditions Obtained}

The optimum values together with the corresponding values of factors which allow to obtain these values are summarized in Table 5 below. These values resulted from the superposition of the three responses surfaces Fig. 2 above. The zone of interest was determined, and it was in that zone where the optimum conditions were found. To the optimum conditions obtained to be valid to the model predicted, these optimum conditions have been triplicated and the results of these replications were compared with the values predicted by the model. This operation of optimization has succeeded regarding the difference between the experimental and the theoretical values less than $5 \%$.

TABLE 5: OPTIMUM VALUES OF RESPONSES

\begin{tabular}{ccccc}
\hline Responses & $\begin{array}{c}\text { Optimum } \\
\text { Values }\end{array}$ & $\begin{array}{c}\text { Activation } \\
\text { Temperature } \\
\left({ }^{\circ} \mathrm{C}\right)\end{array}$ & $\begin{array}{c}\text { Residence } \\
\text { time }(\mathrm{min})\end{array}$ & $\begin{array}{c}\text { Impregnation } \\
\text { ratio }\end{array}$ \\
\hline$Y_{1}(\%)$ & 27.73 & 600 & 60 & $1: 2$ \\
$Y_{2}(\mathrm{mg} / \mathrm{g})$ & 848.25 & 800 & 120 & $1: 2$ \\
$Y_{3}(\mathrm{mg} / \mathrm{g})$ & 9.77 & 800 & 120 & $1: 2$ \\
\hline
\end{tabular}

\section{CONCLUSION}

The factorial plan used helped to determine the optimum conditions for the preparation of activated carbons. The activation temperature and the residence time found to have significant effects on all the three responses investigated. Additionally, the best values of activated carbons yield were obtained for the lowers values of activation temperature and residence time of $600{ }^{\circ} \mathrm{C}$ and $60 \mathrm{~min}$ respectively. On the contrary, for the iodine and methylene numbers, the best values are obtained at higher values of $800{ }^{\circ} \mathrm{C}$ and $120 \mathrm{~min}$ for the activation temperature and residence time respectively. The higher values of iodine numbers obtained between $165.1-889 \mathrm{mg} / \mathrm{g}$ comparatively to the lower values of methylene blue numbers obtained between $2.84-9.81 \mathrm{mg} / \mathrm{g}$ is a primary proof that, the activated carbons based Balanites aegyptiaca activated with $\mathrm{KOH}$ reagent can be used in the adsorption of molecules of small sizes. Thus, the Balanites aegytiaca is a promising precursor for the preparation of microporous adsorbent which can be useful for the sequestration of micropollutants.

\section{ACKNOWLEDGMENT}

The authors thank the Adsorption and Surface unit of the Department of Inorganic Chemistry, Faculty of Science, University of Yaoundé I, Cameroon and the 2iE, Ouagadougou, Burkina Faso for providing laboratory logistics and the Intra ACP Program PIMASO for financial assistance.

\section{REFERENCES}

[1] A. Laurent, I. Bakas, J. Clavreul, A. Bernstad, M. Niero, E. Gentil, M Z. Hauschild, and T. H. Christensen, "Review of LCA studies of solid waste management systems - Part I: Lessons learned and perspectives," Waste Manag., vol. 34, no. 3, pp. 573-588, Mar. 2014.

[2] N. M. Nor, L. C. Lau, K. T. Lee, and A. R. Mohamed, "Synthesis of activated carbon from lignocellulosic biomass and its applications in air pollution control—a review," J. Environ. Chem. Eng., vol. 1, no. 4 pp. 658-666, December 2013.

[3] D. Kouotou, H. Ngomo Manga, A. Baçaoui, A. Yaacoubi and J. Ketcha Mbadcam, 'Physicochemical Activation of Oil Palm Shells using Response surface Methodology: Optimization of Activated Carbons Preparation', Int.l J. Curr. Res., vol. 5, no 3, pp. 431-438, March 2013.

[4] D. Kouotou, H. Ngomo Manga, A. Baçaoui, A. Yaacoubi and J. Ketcha Mbadcam, "Optimization of Activated Carbons prepared by $\mathrm{H}_{3} \mathrm{PO}_{4}$ and Steam Activation of Oil Palm Shells", J. Chem., vol. 2013, 10 pages, August 2013.

[5] A. Baçaoui, A. Yaacoubi, A. Dahbi, C. Bennouna, R. T. L. Phan, F. J Maldonado-Hodar., J. Rivera-Utrilla, C. Moreno-Castilla, "Optimization of conditions for the preparation of activated carbons from olive-waste cakes". Carbon, vol. 39, pp. 425-432, May 2001.

[6] A. Kwaghger and J. Ibrahim, "Optimization of Conditions for the Preparation of Activated Carbon from Mango Nuts using $\mathrm{HCl}$," Am. J. Eng. Res., vol. 2, pp. 74-85, 2013.

[7] M. Gueye, Y. Richardson, F. T. Kafack, and J. Blin, "High efficiency activated carbons from African biomass residues for the removal of chromium (VI) from wastewater," J. Environ. Chem. Eng., vol. 2, no. 1, pp. 273-281, March. 2014.

[8] D. Kouotou, A. N. Rahman, V. G. Hambate, N. J. Nsami, A. Wahabou, J. M. Ketcha, "Adsorption Equilibrium of Nitrates Ions onto Oil Palm Shells-based Activated Carbons" Global Journal of Science Frontier Research, vol. 18, no 2, 2018.

[9] D. Kouotou, J. Blin, H. M. Ngomo, J. N. Ndi, P. D. B. Belibi and J. M. Ketcha, "Mechanisms Involved in the Removal of Phenolic Compounds from Aqueous Solution Using Activated Carbons Based Palm Kernels Shells", J. Appl. Chem., vol. 6, no 5: pp. 799-807, September 2017

[10] J. N. Ndi, and J. M. Ketcha "The Adsorption Efficiency of Chemically Prepared Activated Carbon from Cola Nut Shells by $\mathrm{ZnCl}_{2}$ on Methylene Blue", J. Chem., ID 469170, pp. 01-7, May 2013.

[11] J. N. Ndi, J. M. Ketcha, S.G Anagho, J. N. Ghogomu, and P. B. Belibi, "Physical and chemical characteristics of activated carbon prepared by pyrolysis of chemically treated Cola nut Shells and its ability to adsorb organics", Int. J. Adv. Chem. Technol., vol. 3, no 3, pp. 01-13, February 2014.

[12] J. Ya'u, U. N. Abdulmalik, A. H. Yaro, B. A. Chindo, J. A. Anuka, and I. M. Hussaini, "Behavioral properties of Balanites aegyptiaca in rodents," J. Ethnopharmacol., vol. 135, no. 3, pp. 725-729, Jun 2011.

[13] M. B. Sagna, A. Diallo, P. S. Sarr, O. Ndiaye, D. Goffner, and A. Guisse, "Biochemical composition and nutritional value of Balanites aegyptiaca (L.) Del fruit pulps from Northern Ferlo in Senegal", Afr. J. Biotechnol., vol. 13, no. 2, pp. 336-342, Jan. 2014

[14] H. O. Sanon, J. A. Nianogo, N. S. Nanglem, and S. Sanou, (December 2005) "Amount of fallen fodder components from Acacia raddiana, Balanites aegyptiaca and Ziziphus mauritiana available to ruminants in selected Sahelian pastures", Livest. Res. Rural Dev., [Online]. vol. 17. pp. Available: http://www.lrrd.org/lrrd17/12/sano17147.htm [Accessed: 12-Mar-2014].

[15] B. Chapagain and Z. Wiesman, "Variation in diosgenin level in seed kernels among different provenances of Balanites aegyptiaca Del (Zygophyllaceae) and its correlation with oil content," Afr. J. Biotechnol., vol. 4, no. 11, pp. 1209-1213, Nov. 2005.

[16] M. Ndoye, I. Diallo, Y. Kegrave, and N. Gassama/Dia, "Reproductive biology in Balanites aegyptiaca (L.) Del., a semi-arid forest tree," Afr. J. Biotechnol., vol. 3, no. 1, pp. 40-46, Jan. 2004.

[17] Baçaoui A., Dahbi A., Yaacoubi A., Bennouna C., F.J. MaldonadoHodar, Rivera-Utrilla J., Carrasco-Marin and F., C. Moreno-Castilla, "Experimental design to optimize preparation of activated carbons for use in water treatment", Environ. Sci. Technol., vol. 36, no 17, pp. 3844-3849, July 2002

[18] R. B. N. Lekene, J. N. Nsami., A. Rauf, D. Kouotou, P. D. B. Belibi, M.I. Bhanger and J.K Mbadcam, "Optimization Conditions of the Preparation of Activated Carbon Based Egusi (Cucumeropsis mannii Naudin) Seed Shells for Nitrate Ions Removal from Wastewater". Am J. Anal. Chem., vol. 9, pp. 439-463, Oct. 2018.

[19] US Environmental Protection Agency Technology Transfer, "Process design manual for carbon adsorption." Oct-1973.

[20] ASTM Standard Test Method D - 4607-86, 1986

[21] Hassler J.W. (1974). Purification with Activated carbon: Industrial, Commercial and Environmental. Chemical Publishing Compagny Inc. New York.

[22] A. C. Lua and T. Yang, Effect of activation temperature on the textural and chemical properties of potassium hydroxide activated carbon prepared from pistachio-nut shell, J. Colloid Interface Sci., vol. 274, pp. 594-601. Jun. 2004 
[23] T. Yang, and Lua A.C, Characteristics of activated carbons prepared from pistachio-nut shells by physical activation. J. Colloid Interface Sci., 267, pp. 408-417, Nov. 2003.

[24] D. Adinata, W. M. Ashri W. Daud, M. K. Aroua, "Preparation and characterization of activated carbon from palm shell by chemical activation with $\mathrm{K}_{2} \mathrm{CO}_{3}$ ”. Bioresour. Technol., vol. 98, pp. 145-149, Jan. 2007.

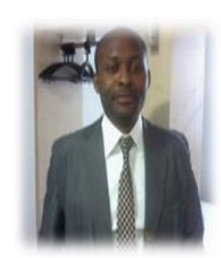

Daouda Kouotou, was born in Ngaoundere, Cameroon. In the year 2014, he obtained a PhD degree in Physical Chemistry at the University of Yaoundé I-Cameroon. He is actually serving as a Senior Lecturer at the Faculty of Science, Department of Inorganic Chemistry, where he teaches Chemical Thermodynamics, Chemical Kinetics and Heterogeneous Catalysis courses.

His research interest is based on valorization of agricultural wastes for the production of outstanding adsorbent materials applied in environmental protection; air, water and wastewater treatment. He has published till now more than twenty scientific papers. 